Fecha de recepción: diciembre 2017

Fecha de aceptación: marzo 2018

Versión final: julio 2019

\section{Imaginarios hipermediáticos. Los mundos visuales del gobierno de Cambiemos (2015-2018)}

Mariano Dagatti ${ }^{\star}$ y Paula Onofrio ${ }^{\star 2}$

\begin{abstract}
Resumen: Las imágenes tuvieron históricamente un rol fundamental en la construcción de identidades políticas en las democracias occidentales. Desde los documentales políticos a principios del siglo XX hasta los álbumes familiares de los políticos en Facebook e Instagram, han contribuido decididamente a la elaboración, expansión y sedimentación de nuestros imaginarios sociales. La denominada sociedad "hipermediatizada” agregó nuevas capas de producción, circulación y consumo de esta faceta espectacular de la política. Nuestro artículo estudia las formas de visualidad y los modos de representación que se organizan en torno al Estado nacional en la Argentina contemporánea, bajo el gobierno de la coalición Cambiemos (2015-2017). Por un lado, se trata de una cartografía de la gráfica política oficial en un período particularmente productivo de imágenes de la política. Por el otro lado, intenta describir sus estéticas dominantes, los modos de organizar su puesta en escena, los modos de imaginar la política, con el objetivo ulterior de echar luz sobre los modos de funcionamiento de una hegemonía discursiva. El trabajo intenta dar cuenta de la dimensión espectacular de la comunicación oficial estatal, y su poder en la construcción de un nuevo colectivo de identificación.
\end{abstract}

Palabras clave: imagen - política - Cambiemos - hipermediatización - colectivo de identificación.

[Resúmenes en inglés y portugués en las páginas 90-91]

${ }^{(*)}$ Mariano Dagatti. Investigador asistente de CONICET por el Centro de Investigación en Economía y Sociedad de la Argentina Contemporánea (UNQ). Doctor en Lingüística y Magister en Análisis del Discurso por la Facultad de Filosofía y Letras de la Universidad de Buenos Aires. Es profesor asistente de Semiótica de los Medios II (FSOC - UBA).

${ }^{\left({ }^{2}\right)}$ María Paula Onofrio. Licenciada en Ciencias de la Comunicación (FSOC - UBA). Actualmente, cursa la Maestría en Diseño Comunicacional de Facultad de Arquitectura, Diseño y Urbanismo (UBA). En el ámbito académico, se desempeña como Becaria UBACyT de Maestría y como ayudante de cátedra de la materia Diseño Gráfico (FADU - UBA). Además, participa en diferentes proyectos de investigación en el marco de la Universidad de Buenos Aires. 


\section{Introducción}

Desde los noticieros y documentales políticos a principios del siglo XX hasta los álbumes familiares de los políticos en Facebook e Instagram, las imágenes tienen un rol fundamental en la configuración del juego político. Si la televisión le devolvió el cuerpo después de un período marcado por el predominio de la palabra (impresa u oral), no parece aventurado sugerir que Internet y los nuevos dispositivos de la conectividad provocaron una mutación de los regímenes de visibilidad, de los modos del darse a ver de la política. Así, la complejidad creciente de la mediatización comporta nuevas dinámicas de producción, circulación y consumo de sus diferentes órdenes de significación.

Inserto dentro del marco de una investigación sobre hegemonía discursiva e identidades políticas en la Argentina contemporánea, nuestro artículo ofrece resultados preliminares de una indagación en curso de las formas de visualidad y los modos de representación de los Estados nacional y subnacionales en la Argentina, bajo el gobierno de la coalición Cambiemos (2015-2017). El estudio de los imaginarios políticos es una vía privilegiada de acceso al estado del discurso social y, de manera específica, al del campo político ${ }^{1}$.

\section{La imaginación gubernamental de Cambiemos (2015-2018)}

¿Qué nos dicen las imágenes de una fuerza política, qué nos dicen en su multiplicidad del mercado discursivo de la política? Bajo el caos aparente de series y capas de enunciados, cada vez más acelerados y reticulares en su circulación, cualquier fuerza política despliega formas regulares de visualidad; ofrece modos de imaginar la política.

Las imágenes persuaden, y su capacidad de seducción ha sido -cuando no temida o negada- descuidada, menospreciada. Indagaremos aquí un aspecto básico de la política contemporánea, que está ligado de manera estrecha a los mundos visuales desplegados en y por las sociedades de la convergencia. Nos ocuparemos de la comunicación (audio) visual del gobierno de Cambiemos (2015-2018), teniendo en cuenta aquellas imágenes e imaginarios que circularon por distintos soportes y formatos de comunicación, desde los afiches en la vía pública hasta las diferentes redes digitales. Con vistas a explorar su imaginación hipermediática ${ }^{2}$, estudiaremos las publicaciones y los posteos de la cuenta oficial de Casa Rosada en distintos medios digitales, a saber: Instagram, Facebook, Twitter, Youtube y su página web. Nos interesa describir sus coordenadas visuales dominantes a partir de su objetivación en formas discursivas concretas.

La metodología de trabajo es la siguiente. A partir de un corte sincrónico, relevamos piezas (audio)visuales que el gobierno nacional produjo durante la presidencia de Cambiemos -desde el 10 de diciembre de 2015 hasta el 22 de octubre de 2018-. Definimos enseguida las regularidades percibidas y planteamos cinco lógicas predominantes, que engloban la enorme mayoría de imágenes observadas ${ }^{3}$. Enseguida se proponen descripciones provisorias sobre las características imaginarias de cada una de ellas y se infieren, sobre la base de estas, el arsenal de medios argumentativos que constituyen prima facie nodos del sistema global de producción, distribución y estratificación de su imaginación gubernamental hipermediática. 
No desconocemos que la definición de un corpus de trabajo se presenta como una primera limitación, ya que la irrupción del sistema de medios con base en Internet y las redes sociales digitales han generado una proliferación exponencial de las imágenes políticas. El sistema de medios masivos -la difusión de un spot en canales televisivos, por ejemplocoexiste con una decena de cuentas oficiales en Internet que emiten publicaciones a diario, volviendo cada vez más difícil la tarea de un abordaje integral. Sin embargo, creemos que es posible -y necesario desde el punto de vista metodológico- la construcción de tipologías que nos permitan organizar, aunque sea de manera provisoria, la propuesta visual del gobierno de Cambiemos. Con este propósito, tendremos en cuenta las lógicas mediáticoinstitucionales de producción de imaginarios en tiempos corrientes de gestión ${ }^{4}$.

¿Cómo se muestra el Estado bajo el gobierno de Cambiemos? ¿De qué modo la propuesta visual del partido gobernante regula los procesos de identificación y los modos de agenciamiento en torno a sus enunciados visuales? Con más dudas que certezas en esta instancia, nos interesa reflexionar sobre esa multiplicidad de imágenes que dan cuerpo al gobierno nacional y lo ponen en escena como actor decisivo. Tomando en cuenta el corpus de trabajo, advertimos que la comunicación política del gobierno de Cambiemos presenta diferentes líneas de "imaginación" que sugieren la convivencia de dinámicas significativamente disímiles entre sí, aunque de ninguna manera contradictorias.

\section{Las lógicas imaginarias de Cambiemos}

Desde recetas para hacer locro o pastelitos hasta la visita de Angela Merkel o del presidente del Comité Olímpico Internacional, desde las inauguraciones de obras públicas hasta las conferencias de prensa y spots institucionales, el repertorio de enunciados visuales del gobierno de Cambiemos es tan amplio como uno pueda imaginar. A nuestro modo de ver, esta amplitud supone en producción una hipótesis acerca de la política y acerca de los asuntos de interés ciudadano. Trataremos en las próximas páginas de brindar argumentos en esta dirección y de extraer conclusiones provisorias con vistas a futuras investigaciones. Nuestro objetivo es aquí dar cuenta de esa multiplicidad de tipologías y estéticas imaginarias, con el propósito de emprender en futuros trabajos algunas aproximaciones a la gramática de producción global que las sostiene. Como resultado preliminar de nuestro relevo, detectamos al menos cinco lógicas de imágenes: la lógica del gobierno próximo, la lógica del Estado-máquina, la lógica del gobierno pastoral, la lógica del gobierno transparente y la lógica del gobierno-protocolo. Estas lógicas se intersecan, se superponen cotidianamente, se refuerzan o se segmentan en función de targets más o menos específicos, pero de ninguna manera se excluyen. A continuación, nos referiremos muy brevemente a cada una de ellas y a sus principales características.

\section{La lógica del gobierno próximo}

Esta es quizás la más novedosa respecto de otros imaginarios políticos en la Argentina contemporánea. Prevalece en Instagram y Youtube, lleva al extremo la ampliación del de- 


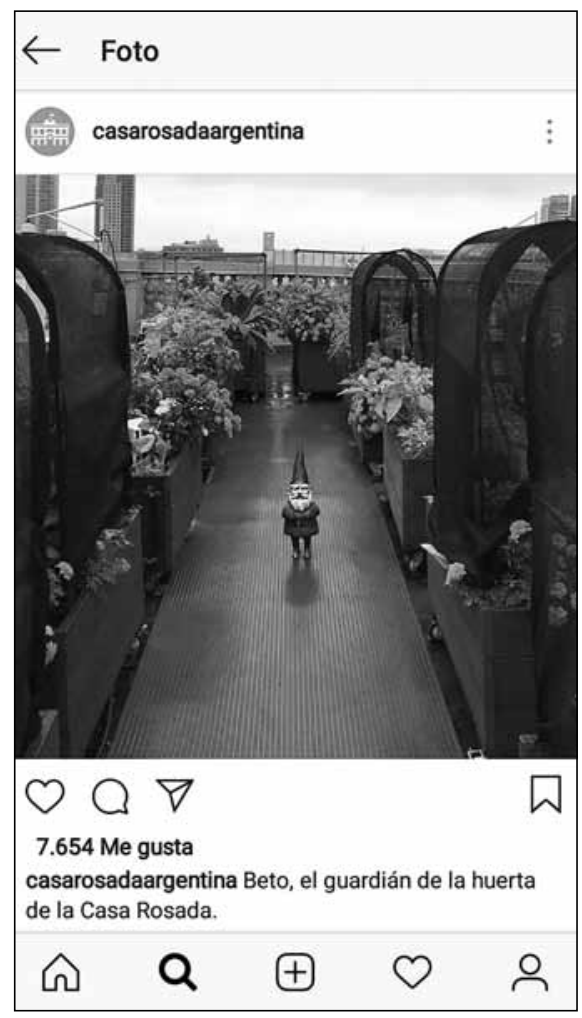

Figura 1. Beto, el guardián de la huerta. Imagen de dominio público.

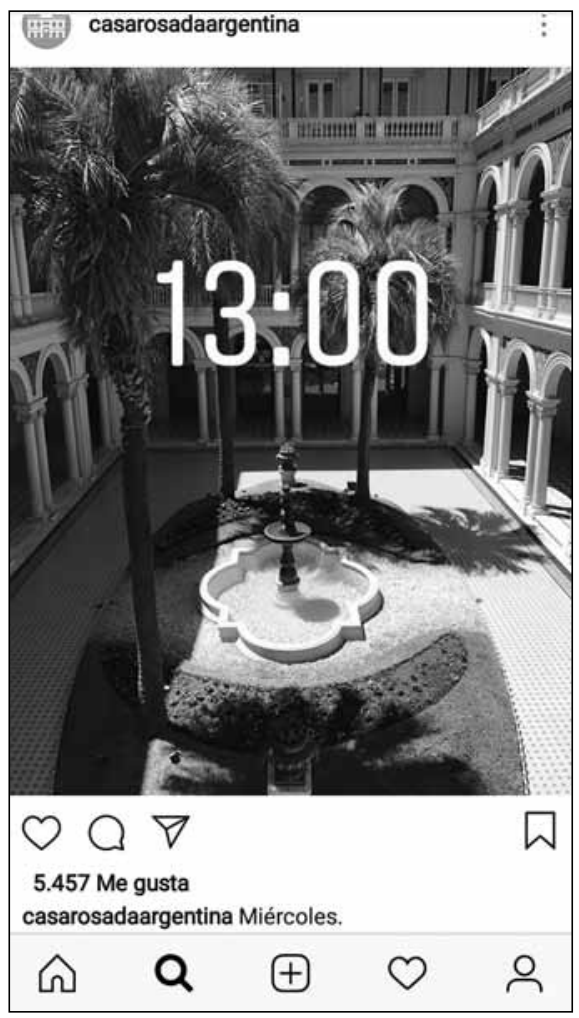

Figura 2. Miércoles. Imagen de dominio público.

cir -o imaginar- político: desde un posteo sobre el amanecer en la Casa Rosada hasta fotografías objetuales o lúdicas: una foto nadir de parte de la fachada de Casa de Gobierno o una del duende Beto, "el guardián de la huerta de la Casa Rosada" (Figura 1).

La mayoría de las publicaciones se inscriben en esta lógica en el caso de Instagram. Las fotografías o videos cortos (nunca superan los treinta segundos) ponen en escena mañanas y tardes, lluvia y sol, interiores y exteriores de la Casa Rosada, detalles arquitectónicos y vistas desde los balcones, espacios vacíos y ocupados. Se trata, por un lado, de espacios, atmósferas y climas que ponen en escena la cotidianidad en y desde la calle Balcarce: una suerte de detrás de escena tan cotidiano cuanto informal, fuera de todo protocolo. El uso recurrente de los stickers que posibilita la aplicación, con la hora o la temperatura, refuerzan el sentido deíctico del posteo y el sentido noemático de la imagen, recordándonos que "es ahora y estamos acá" (Figura 2). 


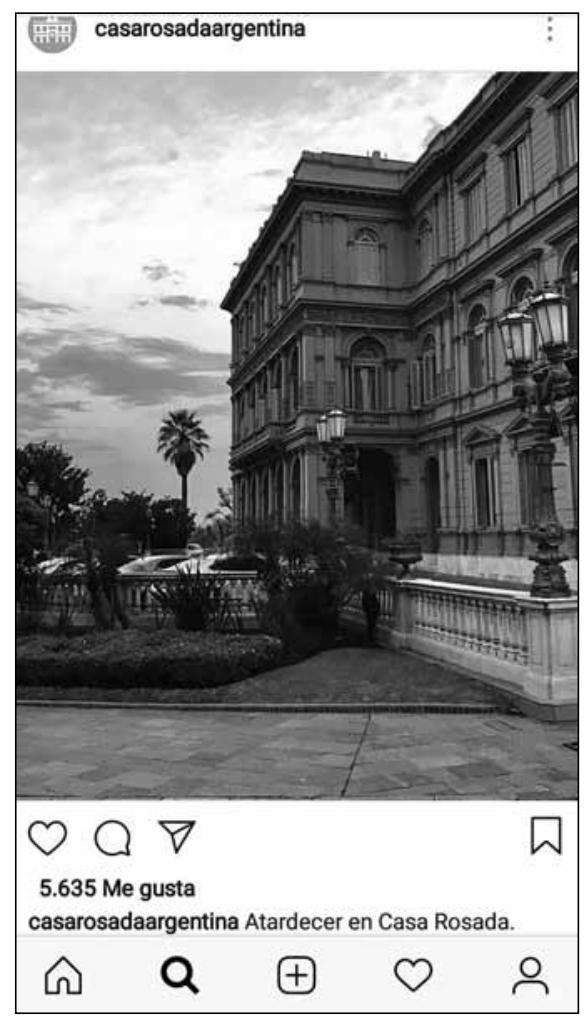

Figura 3. Atardecer en Casa Rosada. Imagen de domino público.

Sin importar tanto qué es lo que se dice, hay toda una zona del imaginario de Cambiemos que apuesta a la política del relación asidua, frecuente, cotidiana. Estar en contacto, en diálogo, chequear la vigencia del canal: es la función fática del lenguaje, que complementa aquella otra, la expresiva, la de un emisor dispuesto a mostrarse bajo códigos estetizantes vueltos lugares comunes de la era de Internet (Prada, 2018). Más aún, hablamos de una verdadera estetización de la vida cotidiana (Lipovetsky y Serroy; 2015), que integra en ella una dimensión estético-emocional (Figura 3). Como sea, las dos funciones del lenguaje demostrarían en buena medida la adaptación del usuario "Casa Rosada" a la lógica de los medios conectivos (Van Dijck, 2016).

En Youtube, aunque de forma esporádica y con otra dinámica, el gobierno próximo reaparece en forma de breves tutoriales que combinan animación y personificación. En menos 


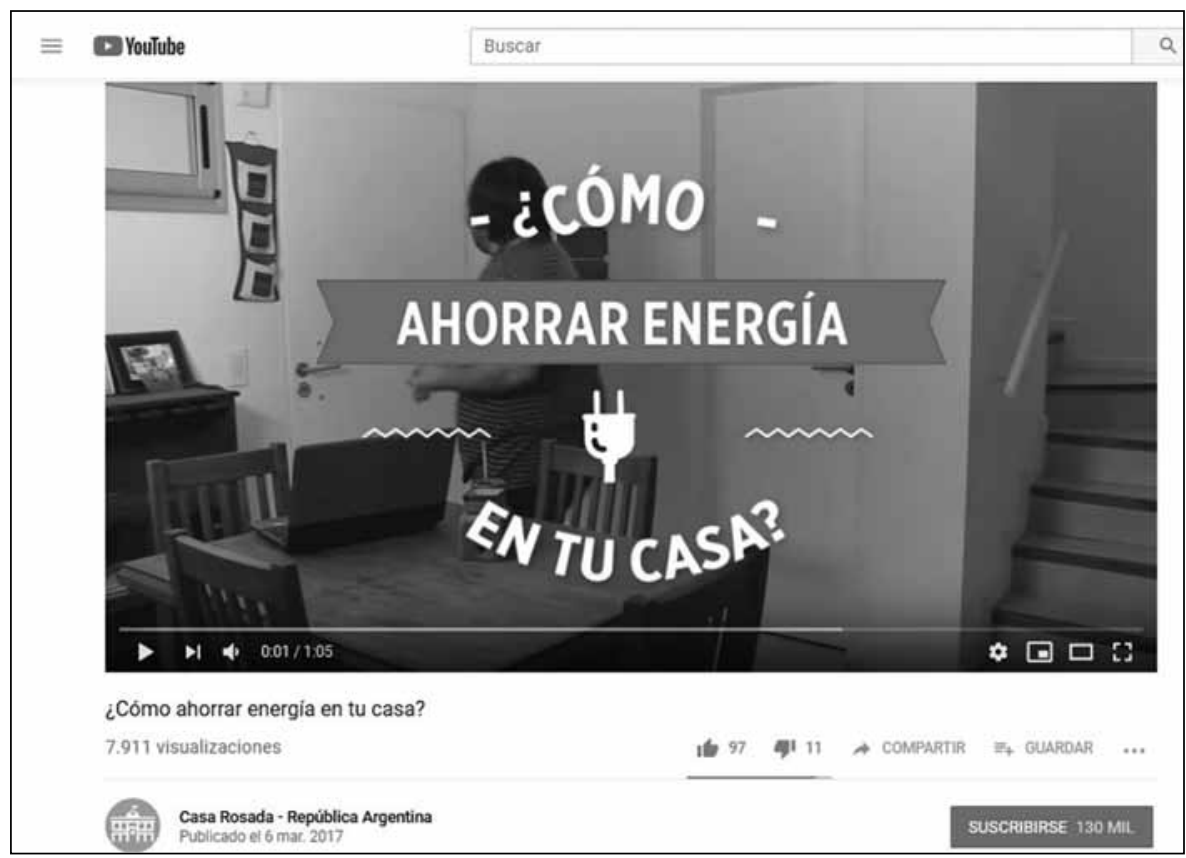

Figura 4. ¿Cómo ahorrar energía en tu casa? Imagen de dominio público.

de dos minutos los videos nos enseñan desde "cómo hacer huevos de pascua" o "cómo hacer un buen locro" hasta "cómo ahorrar energía en tu casa". La combinación de tipografías san serif y cursivas con íconos animados sugieren frescura y proximidad.

Observamos en los enunciados visuales de Cambiemos, de forma transversal, un tipo de enunciación que oscila entre el imperativo juvenil ("sumate", "anótate", "participá") y una pedagogía cuyo tono es menos el de la asimetría gnoseológica que el de una complicidad familiar. Con otras palabras, los componentes pedagógico y prescriptivo, inspirados en manuales de instrucciones o recetarios, aparecen difuminados por un registro lozano, coloquial e informal, que es reforzado por el voseo imperante ("Utilizá lámparas de bajo consumo o led", "Lavá tu ropa con programas económicos o de agua fría") (Figura 4). Ampliación de los imaginarios políticos por adaptación a las memorias discursiva, comunicacional y semiótica de las prácticas de comunicación digital, este tipo de juego en las 
redes sociales inserta a la política en el terreno de lo cotidiano en un doble sentido: por un lado, los temas refieren a situaciones pedestres, mundanas, lúdicas, poniendo en valor lo que es común y habitual para los ciudadanos-followers; por otro lado, ponen en escena un uso de las redes sociales al que estamos acostumbrados más allá de la esfera política: en Instagram publicamos nuestros "aquí y ahora" y en Youtube buscamos, sabiendo que vamos a encontrar, todo tipo de tutoriales. La referencia interdiscursiva a los temas, las estrategias de comunicación y los estilos y tonos de las redes sociales digitales construye un imaginario de gobierno próximo, amistoso, accesible.

\section{“Haciendo lo que hay que hacer": el Estado-maquina}

De lo cotidiano a lo trascendental. Como contracara de la ostentación de proximidad, detectamos en el repertorio de imágenes del Gobierno de Cambiemos una segunda lógica visual: la del Estado-máquina. Esta dinámica despliega un imaginario de la eficiencia, inspirando en una cierta deontología ajena a la voluntad o el deseo subjetivo: "Haciendo lo que hay que hacer" es el slogan de una serie de audiovisuales y afiches que nos sugieren, mediante la argumentación por el ejemplo, que el paroxismo de gobernar es hacer. Los spots institucionales -en el canal de YouTube, pero también en la web de la Casa Rosada-, los afiches en la vía pública y el sistema de mailing son los principales dispositivos de comunicación que esta segunda lógica impregna.

Decimos Estado-máquina y no gobierno máquina, porque se juega en esta lógica la principal apuesta estatista del gobierno: una suerte de reivindicación de la obra pública como deber estatal más allá de todo agente político responsable. Es una operación que se orienta en dos direcciones: de un lado, una suerte de despersonalización del proceso, que pone el peso en la acción y no en el actor: abundan las nominalizaciones, las pasivas, las formas no personales del verbo (sobre todo gerundio, también infinitivo); del otro lado, una suerte de colectivización del proceso, que pone el peso en las consecuencias de la ejecución a partir de apelaciones a formas inclusivas del "nosotros": "Juntos estamos haciendo una ciudad más verde", "Juntos estamos logrando lo que nos propusimos". El Gobierno-actor -cuya firma solemos, no obstante, percibir, ya sea como "Presidencia de la Nación" o "Gobierno de la Ciudad", e incluso a veces con palabras finales de sus principales dirigentes, Mauricio Macri en primer lugar- se difumina en el anonimato casi total o en colectivos de identificación nacional, a partir de la inscripción enunciativa. El contraste con la administración anterior es explícito no sólo por esta suerte de borramiento del agente, sino también porque el componente prescriptivo que suele modalizar la obra pública aparece como contracara moral de aquellos que no hicieron lo que había que hacer (Figura 5).

El uso de fotografías o de registros audiovisuales documentales -con el sonido crudo y sucio de la grabación de las máquinas trabajando, por ejemplo- oficia la constatación de las realizaciones, genera un efecto autentificante. Los spots, los afiches contienen por lo general planos generales o panorámicas, que exponen el carácter monumental de las obras: una especie de paisaje maquínico que recuerda el registro visual de paisajes naturales. 


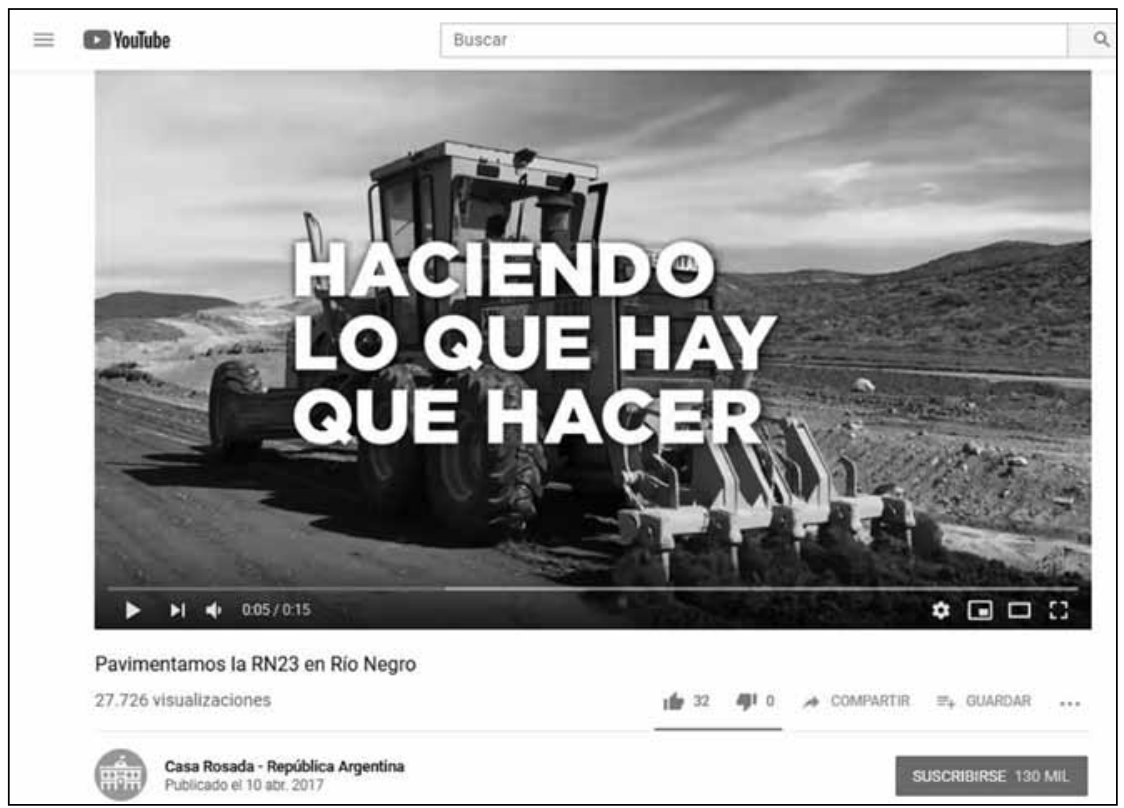

Figura 5. Haciendo lo que hay que hacer. Imagen de dominio público.

La transmisión de los actos de inauguración de obras públicas, encabezados por Macri y funcionarios de su equipo, sugiere una lógica similar. Por un lado, y en un claro gesto de oposición a los actos de los gobiernos kirchneristas, las transmisiones carecen de cualquier tipo de símbolo político-partidario y de cualquier tipo de dispositivo de asimetría: no hay banderas, no hay marchas, ni escenarios y mucho menos atriles. La austeridad de las puestas en escena nos ofrece la imagen de un gobierno sobrio, eficiente, preciso, tan lacónico cuanto espectacular (Figura 6). Por otro lado, los inserts de planos generales que muestran el proceso de la obra y el producto terminado, mientras se van sucediendo los discursos de los funcionarios, contribuyen a reforzar la idea de eficacia, "la pasión por el hacer", sobre la cual ha insistido el presidente en repetidas oportunidades.

La lógica del Estado-máquina es habitual también en los e-mails de los gobiernos subnacionales de Cambiemos, por ejemplo, el de la ciudad de Buenos Aires. Mensajes cuyo asunto es: "Mariano, hablemos de la seguridad en tu barrio"; mensajes que invitan al diálogo y al encuentro, que combinan tramos didácticos y propositivos: "Hola, Mariano, ¿cómo estás? Escucharnos e intercambiar opiniones es una buena manera de seguir mejorando la seguridad de la Ciudad juntos. Por eso te esperamos este jueves a las $18.15 \mathrm{~h}$ en tu Comisa- 


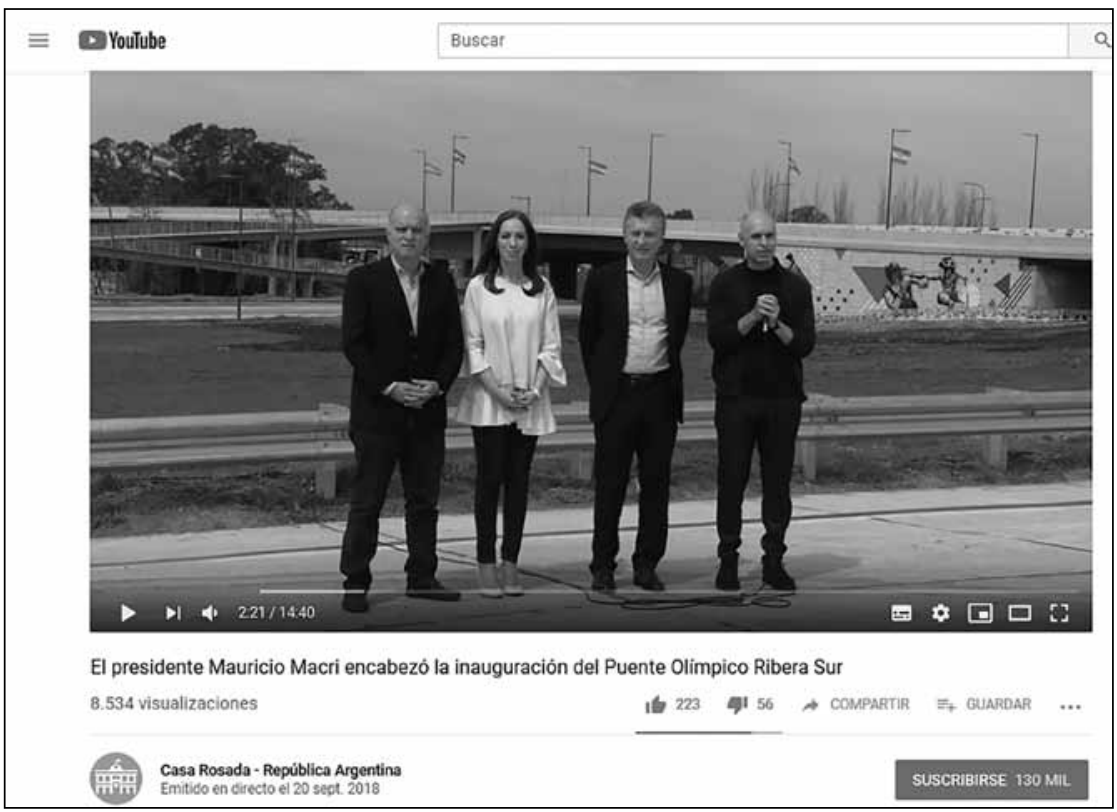

Figura 6. Inauguración del Puente Olímpico Ribera Sur. Imagen de dominio público.

ría más cercana para conversar con las autoridades de la Policía sobre todo lo que podemos hacer para cuidar el barrio". Dentro del imaginario de Cambiemos, la mención de la gran obra pública no opera en desmedro de la pequeña obra en el barrio -como la poda o la limpieza de los sumideros- o del comedido gesto vecinal, como sacar la basura a horario. Desde una ruta nacional hasta el desagüe de $t u$ calle, lo importante es lo concreto y lo visible de esa obra como dispositivo de contacto entre el Gobierno y el ciudadano. Es una dimensión tangible de la gestión. Sin embargo, esta veta tan palpable coexiste con una idea de eternidad o intemporalidad que la obra pública ofrecería a los ciudadanos: "Una ruta es para siempre. Un puente es para siempre. Una red de agua es para siempre. No es solo para hoy, es para siempre. Y lo que se hace para siempre es lo primero que tenemos que hacer [...] Parece mentira que estemos hablando de algo tan básico como abrir una canilla y que salga agua limpia, ¿no?”, narra uno de los spots del gobierno. El largo plazo de la obra pública -la intemporalidad del Estado- contrasta en Cambiemos, como de costumbre, con el corto plazo del populismo. Al mismo tiempo, la trascendencia de la acción pública no carece de un carácter doméstico, próximo, hogareño: la red de agua y abrir una canilla. Eficiencia, trascendencia y tangibilidad de la obra pública son elementos claves. 


\section{La lógica del gobierno pastoral}

Consistente rechazo a la figura del líder carismático, la despersonalización de la imagen del Gobierno, que puede ser entrevista como una suerte de estatización de la gestión contraria a la personalización del gobierno anterior, nos conduce a explorar una tercera zona dentro del imaginario gubernamental de Cambiemos: la del gobierno pastoral.

Este estrato imaginario se basa en dos dinámicas complementarias, que llamaremos totalizante e individualizante. El colectivo y el individuo, y en el medio una suerte de circulación irrestricta de las voces de todos y cada uno de los ciudadanos, facilitada por la coordinación de la dirigencia política. Sin cajas negras, sin secretos, sin dobles fondos. La clave es la predisposición a la escucha, al intercambio de pareceres; es la preocupación por todos, como colectivo nacional, y por cada uno, valorado en su estricta condición de individuo. Seres desiguales, diversos, pero equivalentes, que contribuyen desde su lugar, desde su experiencia, en el funcionamiento del conjunto.

Abundan en el imaginario del partido gobernante las puestas en escena de ciudadanosvecinos, cuyo emblema son los timbreos. Se trata de una visión agregativa, individual y conectiva de la política, que presenta dos grandes nodos semióticos. El primero es una idea de política a mano, no menos tangible que abrir una canilla y que salga agua limpia. Las fotografías o filmaciones que registran los timbreos muestran dos, tres, cinco personas, representados y representantes, conversando, sonriendo. Quienes escuchan suelen ser los políticos; quienes hablan, los vecinos. La proxémica de los cuerpos permite inferir un trato a menudo personal, sin mediaciones. El segundo es una idea de esfuerzo individual que redunda en la construcción colectiva. Por ejemplo, el caso del famoso spot que se desarrolla a partir de la pregunta: “¿Qué se necesita para hacer una empanada?”. La enumeración, en clave de respuesta, va desde Edgardo, el criador de vacas, hasta María Teresa, "una abuela con buena mano para el repulgue". Una lista de individuos cuya tarea, cotidiana y específica, el gobierno conecta e incentiva a partir de la obra pública, el transporte o de los créditos a la producción. La cadena de montaje es reproducida en abismo por la narración misma del video: el gobierno realiza un montaje de las tareas de los individuos que es remedada por la "conexión" sintagmática de cada escena que oficia el enunciador audiovisual, una sucesión agregativa de actores y acciones. La labor de una vasta red de individuos confluye en una sintética empanada, como la red de agua significa abrir una canilla y que salga agua potable. El todo y la parte, la causa y el efecto, la gestión de lo tangible (Figura 7).

La segunda dinámica dentro de la lógica pastoral está vinculada a la noción de "equipo". En oposición al concepto de "liderazgo individual" ligado a la matriz romántica que había estructurado la concepción kirchnerista de la política ${ }^{5}$, la valoración del trabajo en equipo pone en sintonía a la praxis política con el mundo moderno.

El cisma conceptual que implica en el imaginario de Cambiemos la oposición líder / equipo rebasa los límites de lo que podríamos denominar "campo político"; esto es, excede con mucho la mera cuestión de las formas de ejercitar la política: las aparentemente más verticales y tradicionales de los liderazgos del siglo XX, sea uno populista o uno democrático, y las aparentemente más horizontales y a la moda del trabajo en equipo. Ocurre que lo que inicialmente puede ser visto como un simple modo de imaginar una forma de 


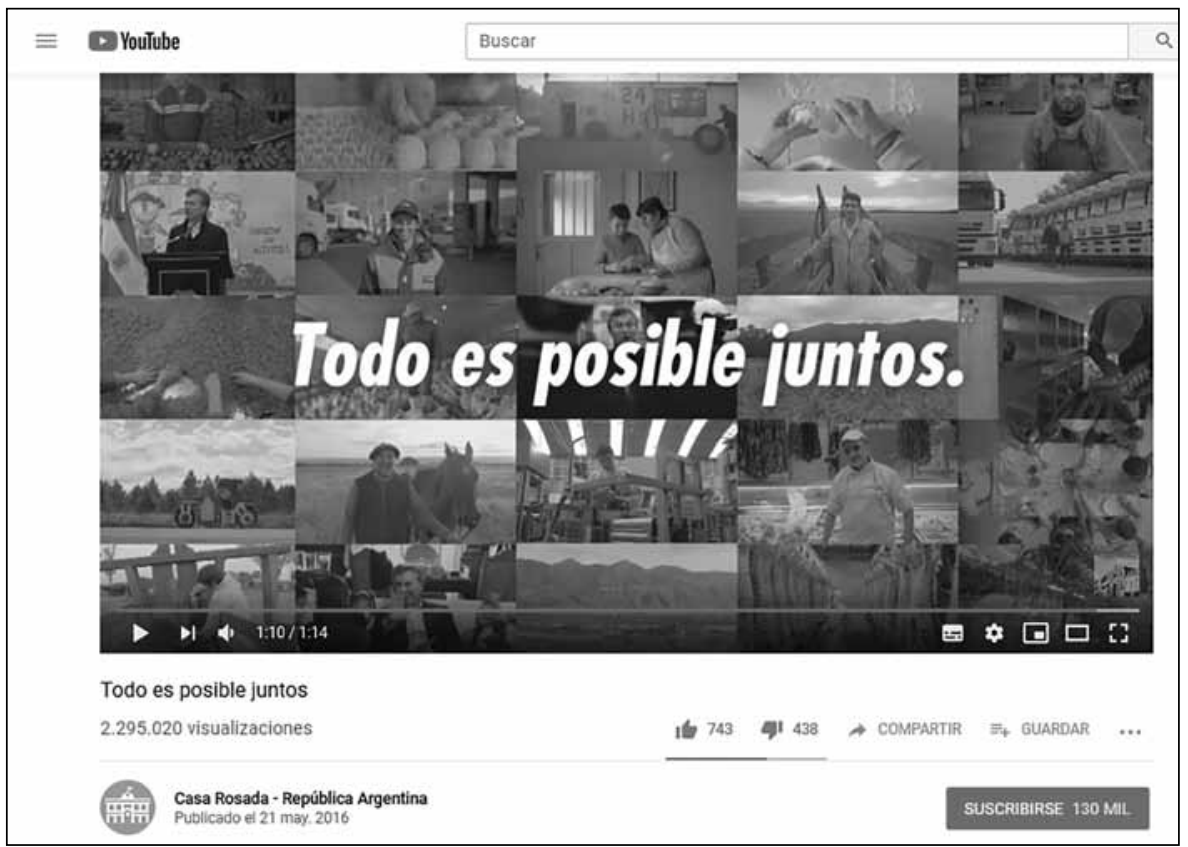

Figura 7. Todo es posible juntos. Imagen de dominio público.

ejercicio de gobierno o, en un sentido más amplio, una forma de praxis política, se revela a una mirada más atenta como una frontera conceptual de índole cultural, que distingue entre una concepción tradicional y una concepción moderna de la organización social. Es una verdadera hermenéutica histórica: a diferencia de los gastados rituales de los líderes, el trabajo en equipo se vuelve la cifra de una visión técnica y profesional del ejercicio de la política, que se pretende plenamente conforme a las características del siglo XXI

Las conferencias de prensa, las entrevistas, la descentralización de las voces autorizadas (ya no el líder carismático, sino un conjunto de voces, a veces en desacuerdo entre ellas, como en el caso ejemplar de Elisa Carrió) dejan ver un énfasis en géneros dialógicos de la puesta en escena (Figura 8). En Hagamos equipo, G. Vommaro y S. Morresi destacan este carácter de ensamble político antes que de asamblea política:

El líder, más que definir ideas, dirigir o cumplir el rol de tomador de decisiones, funciona como un 'armonizador', alguien capaz de escuchar todos los puntos de vista, combinar algunos de ellos e implementarlos de un modo tal que parezca que todos han colaborado en la definición del camino (2015: 54). 


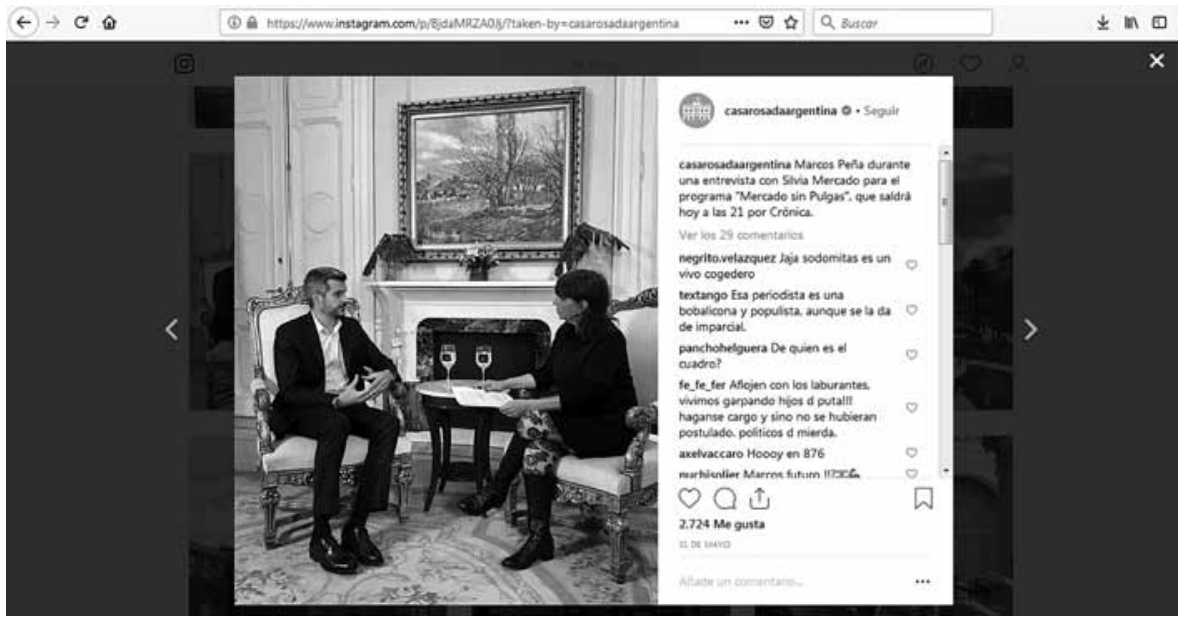

Figura 8. Entrevista con el Jefe de Gabinete, Marcos Peña. Imagen de dominio público.

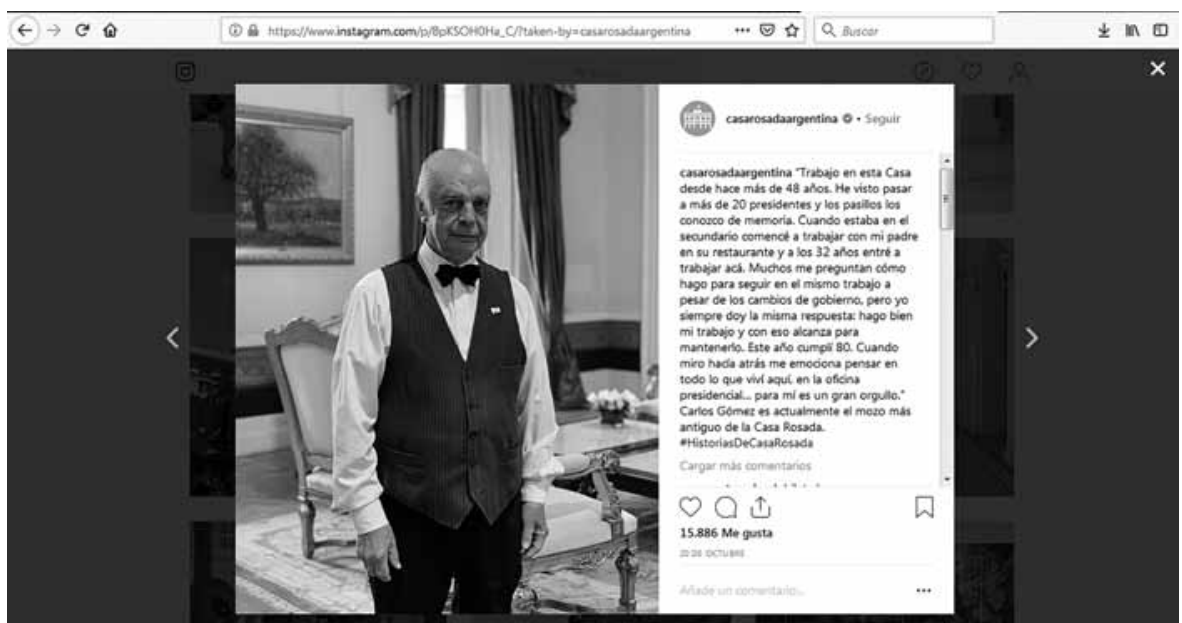

Figura 9. Carlos Gómez, el mozo más antiguo de la Casa Rosada. Imagen de dominio público. 
El líder como montajista, la política como montaje ${ }^{6}$.

Pero no se trata solo de un equipo de gobernantes. Se trata, por ejemplo, de los empleados de Casa Rosada también. Posteo recurrente en sus cuentas de Instagram y Facebook, consiste en el retrato de el/la trabajador/a, acompañado por una breve presentación: "Trabajo en esta Casa desde hace más de 48 años (...)" (Figura 9); "Marta Elvira Gómez trabaja en la Casa Rosada hace 29 años. Forma parte del área de servicios generales". Más aún, no pocas veces la referencia al equipo involucra a todos los habitantes del suelo patrio: "Tenemos que hacer un equipo de 40 millones de argentinos”, declaró Macri al inaugurar un comedor comunitario en Santiago del Estero. "Este equipo de 40 millones de argentinos tiene que ser la generación que cambie la historia del país para siempre”, publicó en su cuenta de Twitter. La gobernadora de Buenos Aires, María Eugenia Vidal, también expresó en el mismo sentido: "Somos un equipo de 40 millones de argentinos" . Describimos entonces una lógica imaginaria que bien podría calificarse de pastoral, en el sentido en que la puesta en escena nos muestra una preocupación, una atención, un interés por todos y por cada uno, por el conjunto y por cada individuo.

\section{La lógica del gobierno transparente}

A las lógicas ya mencionadas dentro del universo visual de Cambiemos podemos agregarle ahora una más: la lógica del gobierno transparente. Esta aparece, sobre todo, en los dispositivos de interfaz más convencionales de Internet, como la web de Casa Rosada. Sus principales tópicos son brindar información, ofrecer estadísticas, volver accesibles balances. Así, por caso, el informe "El estado del Estado", que es puesto a disposición de cualquier usuario a un click de distancia. También se trata de consultar la agenda presidencial o las actividades de la Primera Dama, de conocer los principales programas de gobierno, de ver fotografías, videos y textos de los funcionarios públicos. La información y la accesibilidad se muestran como valores centrales dentro del imaginario del buen gobierno.

Los procesos de interacción con los medios con base en Internet han generado no sólo nuevos tipos de discursos políticos, entre los que se inscribe por ejemplo la ampliación del decir político de Cambiemos, sino también nuevos modos de consumir política, de participar en política y de evaluar o controlar las operaciones del campo político. Los políticos no sólo están bajo la mirada del periodismo, la sociedad en su conjunto ejerce su derecho de vigilancia y denuncia. Y, en este sentido, la capacidad de adaptación de la política se juega no sólo en el uso de una cuenta de Instagram, sino también en la cantidad y calidad de información que un gobierno pone a disposición de cualquier ciudadano.

En el caso de Cambiemos, el gobierno asume a través de sus recursos informáticos un rol facilitador, de aceleración de la experiencia de feed-back: se trata de brindar información, de realizar trámites online, de favorecer las interfaces entre el gobierno y los ciudadanos. Las principales referencias -seis solapas- están en el centro de la web de Casa Rosada, sin un hilo conductor: "Red Sube", "El Estado en tu barrio", "Tarifa social", "Objetivos de gobierno", "Créditos hipotecarios" y "El estado del Estado". Y en una de las solapas superiores se despliega todo tipo de información, sobre todo vinculada a temas sensibles para la opinión pública como la publicidad oficial o los registros de audiencias de los funcionarios 


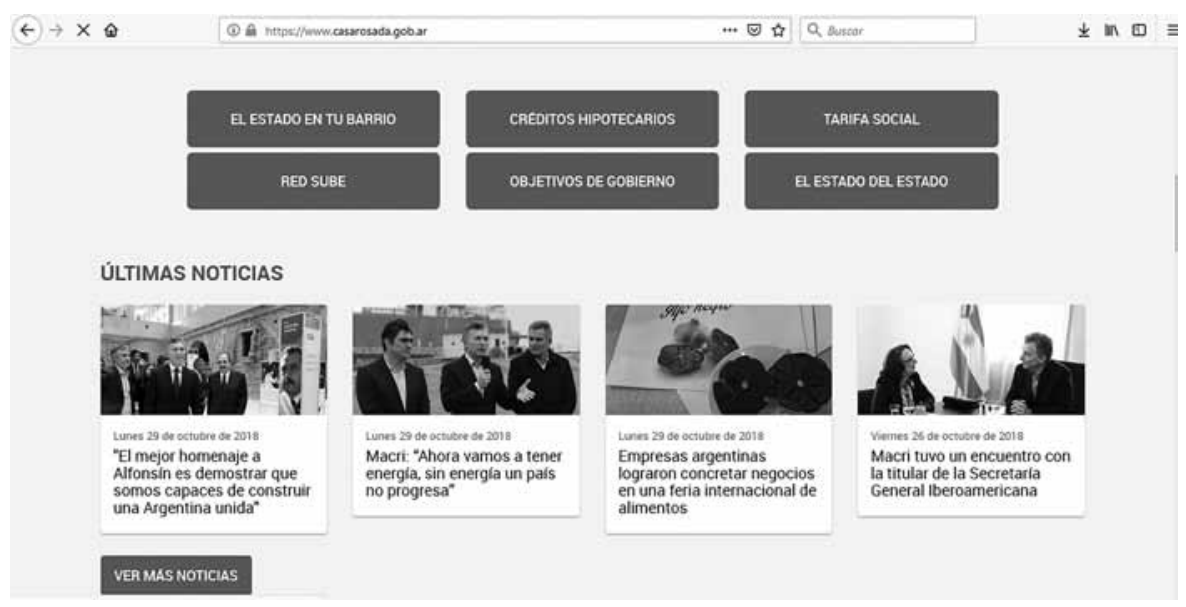

Figura 10. El sitio web de la Casa Rosada. Imagen de dominio público.

(las solicitadas, las concedidas). La interfaz, simple y clara, facilita la navegación y la paleta constante de colores fríos sugiere formalidad, mesura y confianza (Figura 10).

La ostentación de la gestión es también una lógica de imaginación dentro de la retórica de Cambiemos, aunque su lugar suela ser relegado ante la fascinación por las dinámicas más novedosas dentro de su imaginario hipermediático. Al tiempo de la unión y del trabajo en equipo, se le agrega el tiempo de la accesibilidad.

\section{La lógica del gobierno-protocolo}

Finalmente, una lógica distinta construye una cierta distancia que separa al presidente de lo cotidiano y lo convierte en una figura de autoridad: la exaltación de la investidura presidencial y la celebración del protocolo. Aunque ya no opere la proximidad como vector de interfaz entre representantes y representados, se trata de otro modo de poner en escena la celebración de las instancias de diálogo.

Así como ya advertimos que en la cuenta de Instagram de la Casa Rosada predominan motivos lúdicos y estéticos, la cuenta de Twitter está repleta de imágenes sobre reuniones de trabajo y visitas al presidente. Casi sin intervalos, cotidianamente, se nos informa con fotografías adjuntas que "el Presidente recibió hoy en su despacho al presidente de la República de Senegal, Macky Sall", que "el Presidente se reunió con Alfred Kelly, CEO de la compañía global de tecnología Visa Inc.", que "el Presidente recibió en su despacho a William Franke, titular de la aerolínea JetSmart” (Figura 11). Las imágenes que acompañan 


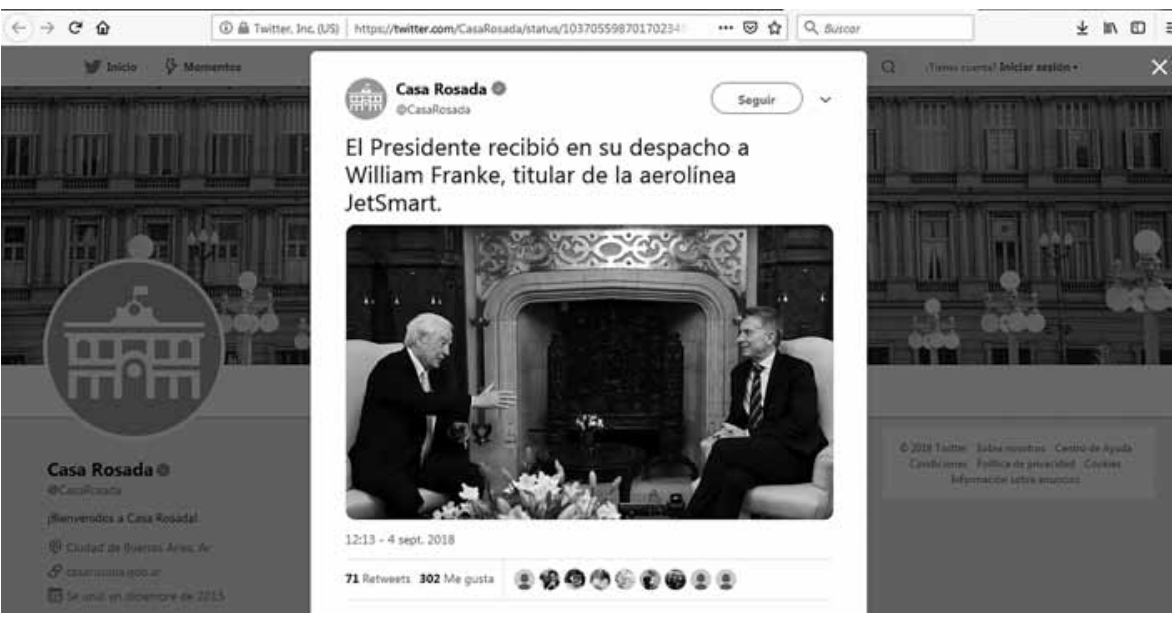

Figura 11. Recepción oficial. Imagen de dominio público.

estas noticias vuelven visible a un presidente o a un grupo de funcionarios que está lejos de los ladrillos sin revoque y de los mates con facturas que alimentan la principal línea de imaginación electoral de Cambiemos (Dagatti, 2018). Con un marcado contraste, la singularidad de su cuerpo en escena dentro de los salones de la Casa Rosada, repletos de detalles lujosos, nos recuerda la distancia que existe entre él, el Presidente, el representante máximo, y nosotros, los ciudadanos.

Jefes de Estado o funcionarios de alto rango de otros países, CEOs de empresas internacionales o nacionales, personalidades reconocidas de la política o la cultura; estos encuentros protocolares, también cotidianos, permiten que los ciudadanos asistan a las funciones habituales del Jefe de Estado. Separan a Macri -y llegado el caso, a sus funcionarios- de los escenarios corrientes de la vida pública y ubican su figura sobre el fondo de las instituciones del Estado.

\section{Consideraciones finales}

Los sistemas de imágenes que acabamos de describir ofrecen pistas sobre un estado del discurso social en nuestro país. El gobierno de Cambiemos ha desplegado imaginarios multifacéticos, que nos hablan de su capacidad de adecuación comunicativa a diferentes dispositivos mediáticos y a los diferentes segmentos poblacionales a ellos asociados. Si Instagram, Facebook, Youtube ofician como redes de contacto cotidiano -atravesadas por la estetización, lo lúdico y la pedagogía-, el sitio web de la Casa Rosada y Twitter priorizan 
una imaginación institucional, protocolar, construyen como lector modelo un ciudadano antes que un usuario-follower empático o interactivo.

Cuando se estudia la imaginación política de Cambiemos como fuerza gobernante es posible advertir su capacidad para entrar en fase con ciertas lógicas contemporáneas de la mediatización de la política y con nuevos estilos de ciudadanía política (Dalton, 2014). Nos referimos al hecho de que la sociedad contemporánea, en su interpenetración con el ecosistema mediático actual, con el escenario de aceleración y multitemporalidad de las NTIC (Rosa, 2010), vivencia una nueva hegemonía de la imaginación de la política que lleva al extremo ciertas características que la denominada "videopolítica" (Sarlo, 1996; Sartori, 1998) había favorecido pero de ninguna manera agotado, mientras disuelve o sanciona de manera negativa otras, más ligadas a una manera clásica -y quizás momentáneamente saturada- de representar el aspecto visible de la política.

Los rasgos distintivos de esta imaginación política serían la apología de la cotidianeidad; la celebración de la inmediatez y la proximidad y la celebración de las instancias de diálogo (y la obliteración de las de conflicto). Su núcleo duro sería el diálogo entre representantes y representados. Fairclough (2008) habla al respecto de "la influencia del discurso conversacional" en los órdenes del discurso sobre la sociedad. Se trata de celebrar la opinión o la expresión de cada individuo sobre los asuntos públicos y, como anverso lógico, de celebrar la escucha, que es, notoriamente, la del político.

El imaginario hipermediático de Cambiemos -su imaginario tramado por memorias y prácticas de los viejos y de los nuevos medios, de los medios masivos y de los medios conectivos- se organiza en torno a un conjunto limitado de argumentos visuales, un "arsenal argumentativo" en términos de Angenot, cuya escasez -cuya rareza- contrasta con la abundancia de enunciados concretos, que circulan por la vía pública, los medios tradicionales, las redes sociales digitales. Estudiamos aquí la multiplicidad de imágenes que dan a ver la gestión gubernamental de Cambiemos. Nos interesa comprender, aunque sea manera parcial y provisoria, las razones de las dinámicas políticas y de los juegos de poder que organizan y orientan nuestros asuntos comunes. Estudiar la imaginación política contribuye a dicha comprensión.

\section{Notas al final}

1. La teoría del discurso social de Marc Angenot hace referencia a "un sistema regulador que predetermina la producción de formas discursivas concretas" (2010:30). Aun cuando a primera vista la proliferación de enunciados dé la impresión de una extrema diversidad de temas, de opiniones, de lenguajes, de jergas y de estilos, un conjunto de reglas prescriptivas de diversificación e integración organiza lo decible y lo pensable de una sociedad en una coyuntura histórica determinada y establece sus límites, divisiones y jerarquías. El discurso social está dividido en campos, que forman un sistema de géneros, de repertorios temáticos y de estilos, ofreciendo una topografía. Cada entidad discursiva puede caracterizarse por una axiomática propia, un campo (donde ella se inscribe y encuentra sus antagonistas eventuales), un status cultural, vínculos institucionales, una función en la circulación de ideologemas como dispositivo intertextual específico, una ideología inmanente 
que le confiere poder y legitimación, una tradición propia, sus participantes acreditados con sus prestigios particulares y sus habilidades. La unidad de un campo dado, como la del campo político que interesa a este artículo, es aquella de un mercado discursivo, es decir un espacio de intercambio y de migraciones de enunciados, marcada por las competencias de los agentes colectivos e individuales que allí operan.

2. Utilizamos indistintamente los calificativos "hipermediático/a" o "hipermediatizado/a" para referir a aquella sociedad contemporánea en la que el ecosistema mediático se caracteriza por la coexistencia del tradicional sistema de medios masivos (radio, televisión, prensa) y el nuevo sistema de mediatización con base en Internet, dominado por los medios que Van Dijck (2016) denomina "conectivos" (redes sociales digitales, por ejemplo). La "sociedad hipermediatizada" -tal la expresión de Mario Carlón (2016)- sería un tercer estadio, después de las sociedades mediáticas y mediatizadas. Sus características han sido trabajadas profusa y sistemática por dicho autor a partir de su apropiación de la teoría de la comunicación de Eliseo Verón. Sobre hipermediatización en la política argentina, los trabajos de referencia son los de Slimovich $(2012,2017)$.

3. El universo observado llegó a la saturación, es decir, la enorme mayoría de las imágenes observadas correspondía claramente a uno de los cinco tipos que identificamos, o a una combinación inequívoca de dos de ellos.

4. Por oposición a lógicas individuales, por un lado, y por oposición a lógicas mediáticoinstitucionales en tiempos de competencia electoral, por otro.

5. Véase Dagatti (2015); de manera específica, el capítulo 5: "La arquitectura de las pasiones kirchneristas: de la matriz romántico-generacional a la matriz romántico-popular”.

6. Ver, por ejemplo, el spot institucional "Nos juntamos": https://www.youtube.com/ watch?v=KOXTfRrXSZQ.

7. Las citas han sido extraídas de: http://www.diariojornada.com.ar/196089/paismundo/ tenemos_que_hacer_un_equipo_de_40_millones_de_argentinos_dijo_macri/; https://twi tter.com/mauriciomacri/status/896926257585074177; https://m.facebook.com/ProArgenti na /photos/a.90125431996/10155627051921997/?type $=3 \&$ source $=57$

8. Véase al respecto un trabajo anterior del autor: "Imágenes de un mundo que cree en las imágenes", en M. Dagatti y V. Sargentini (eds.), Los pueblos de la democracia. Política y medios en el siglo XXI. La Bicicleta Ediciones: Buenos Aires.

\section{Referencias bibliográficas}

Angenot, M. (2010). El discurso social. Los límites históricos de lo pensable y lo decible. Buenos Aires: Siglo Veintiuno Editores.

Dagatti, M. (2015). Imágenes de sí y pathos político. Los discursos públicos de Néstor Kirchner (2006-2009). Tesis entregada para la obtención del título de doctor en la Universidad de Buenos Aires. Disponible en: http://repositorio.filo.uba.ar/bitstream/handle/filodi gital/3017/uba_ffyl_t_2015_903583_v1.pdf?sequence=1\&isAllowed $=y$

Dagatti, M. (2018). Imágenes de un mundo que cree en las imágenes: retóricas visuales de la política en la Argentina contemporánea (2011-2018). En Los pueblos de la democracia. Política y medios en el siglo XXI. Buenos Aires: La Bicicleta Ediciones, pp. 71-94. 
Carlón, M. (2016). Una apropiación contemporánea de la teoría de la comunicación de Eliseo Verón. En Comunicación, campo(s), teorías y problemas. Una perspectiva internacional. Salamanca: Comunicación Social, pp. 125-154.

Dalton, R. (2014). Citizen Politics: Public Opinion and Political Parties in Advanced Industrial Democracies. Los Angeles: Sage Publications, 2014.

Fairclough, N. (2008), Discurso e mudança social. Brasilia: Editora UnB.

Lipovetsky G. y Serroy J. (2015). La estetización del mundo. Vivir en la época del capitalismo artístico. Barcelona: Anagrama.

Prada, J. M. (2018). El ver y las imágenes en el tiempo de Internet. Madrid: Akal.

Rosa, H. (2010): Social acceleration. A new theory of modernity. Nueva York: Columbia University Press.

Sarlo, B. (1996). "Siete hipótesis sobre videopolítica". En Instantáneas. Medios, ciudad y costumbres en el fin de siglo. Buenos Aires: Ariel.

Sartori, G. (1998). Homo videns: la sociedad teledirigida. México: Taurus.

Slimovich, A. (2012). El Facebook de los gobernantes. El caso de Mauricio Macri y Cristina Fernández de Kirchner". En Las políticas de los internautas. Nuevas formas de participación. Buenos Aires: La Crujía.

Slimovich, A. (2017). La ruta digital a la presidencia argentina. Un análisis político e hipermediático de los discursos de Mauricio Macri en las redes sociales. En Revista Dixit, 27, Universidad Católica del Uruguay, Montevideo, pp. 24-43. Disponible en: http://revistas. ucu.edu.uy/index.php/revistadixit/article/view/1321

Van Dijck J. (2016). La cultura de la conectividad: una historia crítica de las redes sociales. Buenos Aires: Siglo Veintiuno Editores.

Vommaro G. y Morresi S. (2015). "Hagamos equipo". PRO y la nueva construcción de la derecha en Argentina. Buenos Aires: Universidad Nacional de General Sarmiento.

\begin{abstract}
The images historically had a fundamental role in the construction of political identities in Western democracies. From political documentaries at the beginning of the 20th century to the family albums of politicians on Facebook and Instagram, they have contributed decisively to the elaboration, expansion and sedimentation of our social imaginaries. The so-called "hypermediated" society added new layers of production, circulation and consumption of this spectacular facet of politics.

Our article studies the forms of visuality and the modes of representation that are organized around the national State in contemporary Argentina, under the government of the Cambiemos coalition (2015-2017). On the one hand, it is a cartography of the official political graphic in a particularly productive period of political images. On the other hand, it attempts to describe its dominant aesthetics, the ways of organizing its staging, the ways of imagining politics, with the ultimate aim of shedding light on the modes of operation of a discursive hegemony. This paper aims at giving an account of the spectacular dimension of the official communication, and its power in the construction of a new mode of identification.
\end{abstract}


Keywords: image - politics - Let's change - hypermediatization - collective identification.

Resumo: As imagens historicamente tiveram um papel fundamental na construção de identidades políticas nas democracias ocidentais. Desde documentários políticos no início do século XX até álbuns de família de políticos no Facebook e no Instagram, eles contribuíram decisivamente para a elaboração, expansão e sedimentação de nossos imaginários sociais. A chamada sociedade "hipermediada" acrescentou novas camadas de produção, circulação e consumo dessa faceta espetacular da política.

Nosso artigo estuda as formas de visualidade e os modos de representação que se organizam em torno do Estado nacional na Argentina contemporânea, sob o governo da coalizão Cambiemos (2015-2017). Por um lado, é uma cartografia do gráfico político oficial em um período particularmente produtivo de imagens políticas. Por outro lado, tenta descrever seus dominantes estéticas, formas de organizar a sua encenação, imaginar formas de política, com o objetivo final de lançar luz sobre os modos de funcionamento de uma hegemonia discursiva. $\mathrm{O}$ trabalho tenta dar conta da dimensão espetacular da comunicação oficial do Estado e seu poder na construção de um novo coletivo de identificação.

Palavras chave: imagem - política - Vamos mudar - hipermediatização - identificação coletiva.

[Las traducciones de los abstracts fueron supervisadas por el autor de cada artículo] 